Int. J. Dev. Biol. 53: 1341-1347 (2009)

doi: $10.1387 / \mathrm{ijdb} .072447 \mathrm{fm}$

\title{
Apoptosis in Drosophila: compensatory proliferation and undead cells
}

\author{
FRANCISCO A. MARTÍN, AINHOA PERÉZ-GARIJO\# and GINÉS MORATA* \\ Centro de Biología Molecular, Universidad Autónoma de Madrid, Madrid, Spain
}

\begin{abstract}
Apoptosis (programmed cell death) is a conserved process in all animals, used to eliminate damaged or unwanted cells after stress events or during normal development to sculpt larval or adult structures. In Drosophila, it is known that stress events such as irradiation or heat shock give rise to high apoptotic levels which remove more than $\mathbf{5 0} \%$ of cells in imaginal discs. However, the surviving cells are able to restore normal size and pattern, indicating that they undergo additional proliferation. This "compensatory proliferation" is still poorly understood. One widely used method to study the properties of apoptotic cells is to keep them alive by expressing in them the baculoviral protein P35, which blocks the activity of the effector caspases. These "undead" cells acquire special features, such as the emission of the growth signals Dpp and Wg, changes in cellular morphology and induction of proliferation in neighbouring cells. Here, we review the various methods used in Drosophila to block apoptosis and its consequences, and focus on the generation and properties of undead cells in the wing imaginal disc. We describe their effects in epithelial architecture and growth in some detail, and discuss the possible relationship between undead cells and compensatory proliferation.
\end{abstract}

KEY WORDS: apoptosis, compensatory proliferation, undead cell, Wg and Dpp signalling

\section{Functional significance of apoptosis}

All animal cells contain inside the instruments of their own destruction, as it is often necessary to eliminate some cells during development or during the life cycle of an organism. This process of self-destruction is called apoptosis and is characterised by a series of morphological changes (condensation of the nucleus and cytoplasm, activation of proteases and nucleases, degradation of proteins and DNA) followed by phagocytosis of dying cells by neighbouring cells or phagocytes (reviewed in Fink and Cookson, 2005, and references therein)

Apoptosis is widely used in nature to sculpt new structures, remove supernumerary cells or useless tissues. It is also important in the immune response and to eliminate damaged or abnormally proliferating cells (reviewed in Baehrecke, 2002). Apoptosis must be strictly regulated, for diminution or lack of apoptosis often results in tumour processes and autoinmunne diseases, whereas the excess of cell death is associated with neurodegenerative diseases (reviewed in Danial and Korsmeyer, 2004).
In this review we focus on some aspects of apoptosis in Drosophila. There are two main reasons that make Drosophila a convenient model to study apoptosis. The first one is the many genetic tools that exist in Drosophila, which permit to devise screens to look for new components of the apoptotic program (for a review, see Hay et al., 2004). The second one is that the apoptotic machinery is by and large conserved in insects and vertebrates (Danial and Korsmeyer, 2004, Riedl and Shi, 2004). Therefore many of the findings made in Drosophila about the properties of the apoptotic cells and the implications in disease will be generally applicable.

\section{Apoptosis in Drosophila}

An outline of the apoptotic machinery of Drosophila is shown in Fig. 1A. The proteins responsible for the destruction of the cells are cysteine proteases, called caspases. There are two types of caspases: apical or initiator caspases, with autocatalytic activity and effector caspases, which are activated by initiator caspases and are responsible for dismantling the cell substrates (for a more

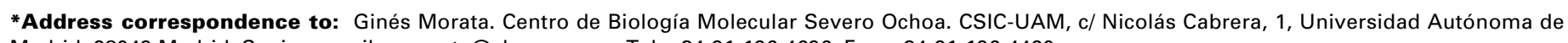
Madrid, 28049 Madrid, Spain. e-mail: gmorata@cbm.uam.es Tel: +34-91-196-4696. Fax: +34-91-196-4420.

\# Present address: The Rockefeller University. 1230 York Avenue, New York, NY 10021, USA.

Final author-corrected PDF published online: 8th May 2008.

ISSN: Online 1696-3547, Print 0214-6282

(c) 2008 UBC Press

Printed in Spain 
detailed study of the Drosophila apoptotic machinery, see Cashio etal., 2005, Hay and Guo, 2006). Caspases are always present in the cells, but as inactive zymogens. They are kept in check by the ubiquitous activity of the DIAP1 (Drosophila Inhibitor of Apoptosis Protein 1) product, which prevents their proteolytic activation. Thus the key issue to control apoptosis is to regulate DIAP1 function, as suppression of DIAP1 activity triggers apoptosis. Suppression of DIAP1 is achieved by the products of the proapoptotic genes reaper (rpr), head involution defective ( hid) and grim (recently another two pro-apoptotic genes sickleand jafrac2 have been identified); their products bind to the DIAP1 protein and induce its proteolytic degradation (Ryoo et al., 2002, Wing et al., 2002). These genes are contiguous in the genome and were probably originated by a tandem duplication of an original proapoptotic gene. A small deletion called $D f(3 L) H 99$ removes the three genes (White et al., 1994).

The rpr, hid and grim genes, and therefore the initiation of apoptosis, may be induced by a series of upstream factors, such as the p53 gene (Brodsky et al., 2004, Sogame et al., 2003) or the Jun N-terminal Kinase (JNK) pathway (Adachi-Yamada et al., 1999. McEwen and Pfeifer, 2005). These two factors appear to canalise developmental or environmental stimuli leading to apoptosis, such as irradiation or cell competition (Brodsky et al., 2000, Moreno et al., 2002, Ollmann et al., 2000)

\section{Developmentally regulated vs. stress response apop- tosis}

Operationally, we can distinguish two types of apoptosis: a "developmentally regulated" apoptosis, part of the normal developmental program, aimed to sculpt organs or for normal morphogenesis (reviewed by Baehrecke, 2002). In the Drosophila embryo, this type of apoptosis is important in different processes (Greenwood and Gautier, 2005). For example, it has been shown that, in early embryos, Deformed, a Hox protein, activates reaper at the boundary between the maxillary and mandibular segments, thus a cleft is formed (Lohmann et al., 2002). There are other examples during imaginal disc development and pupariation. A classical one is the elimination of the excess of interomatidial cells during metamorphosis (Wolff and Ready, 1991). More recently, it has been described a novel morphogenetic role of apoptosis: the formation of the leg joints (the structures that divide the insect leg into segments) requires the activity of reaper, which is induced by a sharp discontinuity of Dpp signalling levels in the presumptive region (Manjon et al., 2007). A second type of apoptosis is induced by stress events (Song, 2005). Although these events are not normally programmed in development, evolution has designed a method to dispose of the cells damaged by insults like irradiation, heat shocks, hypoxia etc.

The wing imaginal disc is a very convenient system to study stress induced apoptosis as it shows very little developmentally regulated apoptosis, thus all observed apoptosis is caused by the stress treatment (Chen etal., 1996, Milán etal., 1997, Pérez-Garijo et al., 2004).

There are a number of treatments that can provoke cell death in imaginal tissue. One way is to irradiate larvae; even moderate doses of X-Ray (1000R-2000R) can eliminate as many as 40-60\% of wing imaginal cells (Haynie and Bryant, 1977). A heat-shock at $37^{\circ} \mathrm{C}$ for 3 hours can also cause high apoptotic levels (Pérez-Garijo et al., 2004). Nevertheless, the most common method to induce experimentally apoptosis is irradiation, so in this review we focus on the wing imaginal cells response to this type of stress.

\section{Genes involved in the apoptotic stress response}

A protein that activates the apoptotic response after irradiation is DmP53, the fly homolog of the product of the tumour suppressor gene $p 53$ (reviewed by Lu and Abrams, 2006). Flies mutant for Dmp53 show very little apoptosis response to X-rays (Lee et al., 2003, Sogame et al., 2003) and similarly, over-expression of a dominant negative form of Dmp53 also inhibits response to irradiation (Brodsky et al., 2000, Ollmann et al., 2000). It has been shown

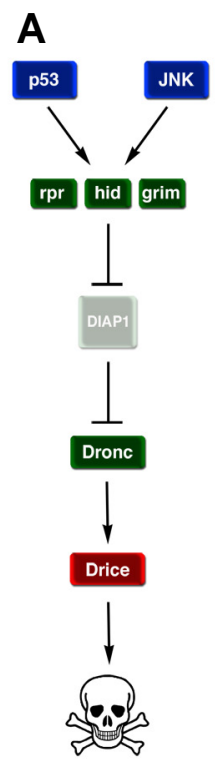

Normal development
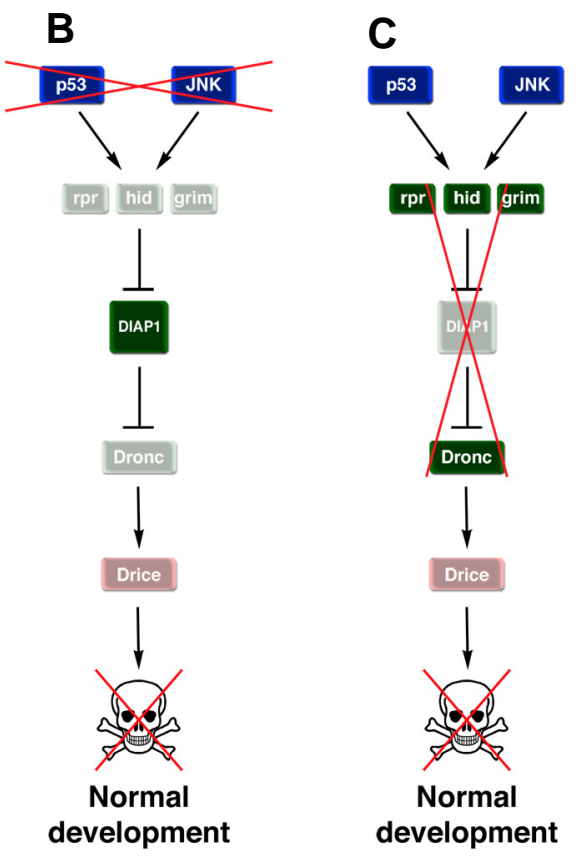

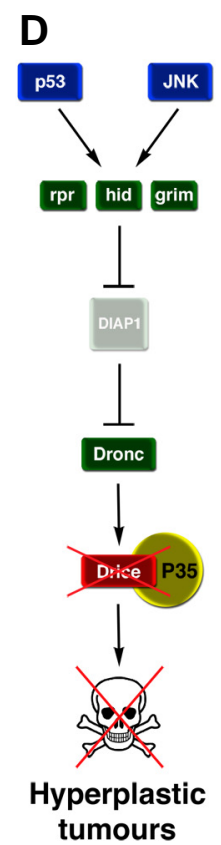

Fig. 1. A schematic view of Drosophila apoptotic machinery. (A) Outline of the various steps of apoptosis induction in Drosophila. Upstream activators like p53 and the JNK pathway, among others, induce one or more of the proapoptotic genes rpr, hid or grim whose products bind to and prevent function of the DIAP1 product. The loss of DIAP1 function allows proteolytic activation of caspases, which results in the destruction of the cell. (B,C,D) The different levels in which it is possible to interfere experimentally with the apoptotic process: at the activity of upstream activators (B), the activation of caspases (C), or the function of activated caspases (D). For details see the main text. 
that pro-apoptotic genes rpr, hid and sickle are transcriptional targets of DmP53and that hidis a major factor in X-ray induced apoptosis in wing disc (Brodsky et al., 2004, Sogame et al., 2003). It has also been reported a delayed Dmp53-independent cell death following irradiation, with caspase activation (Wichmann etal., 2006), but further work is needed to elucidate which mechanisms are involved.

The activity of the JNK pathway also mediates stress-induced apoptosis: after $\gamma$-irradiation, up-regulation of the JNKtarget gene puckered (puc, a phosphatase that functions as a negative regulator of the activity of the pathway) can be observed throughout the entire wing disc (McEwen and Peifer, 2005). $\gamma$-rays-induced cell death can be blocked by overexpressing puc, which suppresses JNK activity (McEwen and Peifer, 2005). JNK activation (and subsequent apoptosis) following irradiation requires Dmp53, ectopic Dmp53 expression can induce apoptosis and activity of the JNK pathway (McEwen and Peifer, 2005). The extant evidence suggests that apoptosis induction by Dmp53 is mediated by JNK activity. The details of the molecular interactions between Dmp53 and the JNK pathway are not entirely elucidated.

Recently, it has been shown a connection between the Hippo pathway (Colombani et al., 2006) and apoptosis: $\gamma$-rays induce Hippo Kinase activity in a Dmp53-dependent manner both in imaginal discs and in cell culture. Moreover, it has been shown that DIAP1 is a target of the Hippo pathway (Saucedo and Edgar, 2007).

A significant feature of stress-induced apoptosis is the large amount of cell death produced by non-lethal treatments. It has been estimated that after a dose of $1000 \mathrm{R}$ more than $50 \%$ of the cells in the wing imaginal disc enter apoptosis. Yet after such events treated animals recover and are able to restore organs of normal shape and size (Haynie and Bryant, 1977, PérezGarijo et al., 2004). This indicates the existence of a phenomenon of compensatory proliferation (Graves and Schubiger, 1982, Haynie and Bryant, 1977): additional proliferation by surviving cells to compensate for the loss of material.

The issue of compensatory proliferation has been subject of intensive research in recent years (see Domingos and Steller, 2007), but little is known about the genes implicated in the response. The genes mei-41 (the fly $A T R$ homolog, a gene necessary to delay the entry into mitosis after incomplete DNA replication or irradiation) and okra (the homolog of the yeast gene RAD54 involved in DNA repair) are required for compensatory proliferations, for in their absence eye-antennal discs do not reach normal size after irradiation, being unable to sustain organized cell proliferation (Jaklevic and Su, 2004).

\section{Interfering with the apoptotic response}

The genetic trickery of Drosophila allows to interfere with apoptosis at different stages of the process: 1 ) at the activation of the apoptotic program by suppressing the function of upstream activators such as p53 or the JNK pathway (Fig. 1B), 2) the activation of caspases (Fig. 1C), 3) the function of the effector caspases (Fig. 1D).

\section{1) Preventing upstream activators}

It can be achieved by blocking the activity of P53, using p53 null
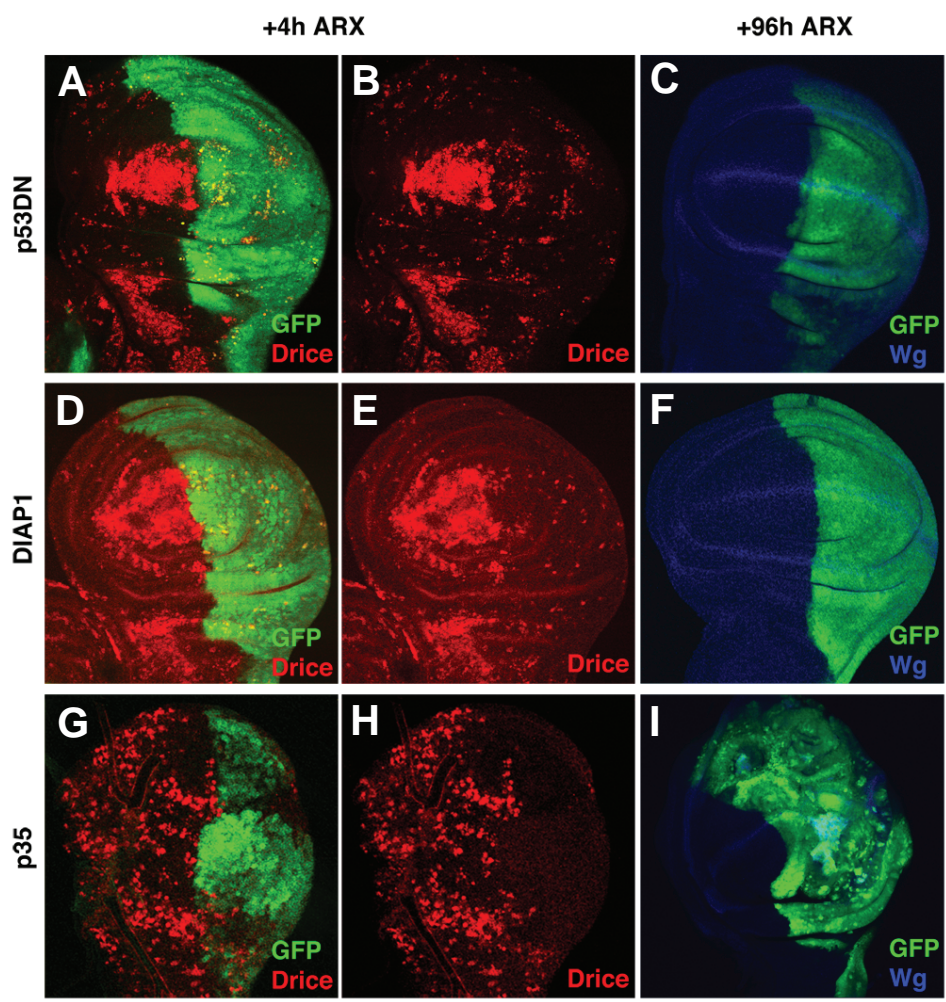

Fig. 2. Interference at different steps of the apoptosis program. (A-C) Wing imaginal disc of genotype hh-Gal4>UAS-p53DN UAS-GFP stained for Drice (red) and Wingless $(\mathrm{Wg}$, blue) $4 h(\mathbf{A}, \mathbf{B})$ and $96 \mathrm{~h}$ (C) after irradiation. In the posterior compartment (labelled green with GFP) there is much less caspase activity than in the anterior one, because loss of p53 function largely inhibits the apoptotic response. However, apoptotic inhibition does not appear to have a major effect, since after 96 h (C) the disc has normal size and morphology. A similar result (D-F) is obtained preventing apoptosis by overexpressing DIAP1 (hh-Gal4>UAS-DIAP1 UAS-GFP): the inhibition of apoptosis in the posterior compartment does not have a major consequence. However, interfering with the function of the active caspase (G-I) with the baculoviral protein P35 (hh-Gal4>UAS-p35 UAS-GFP) gives rise to overgrowth and aberrant morphology of the posterior compartment.

mutants or transgenes containing a dominant negative form of the gene (UAS-p53 DN) which permit a spatial and temporal regulated inactivation of P53 function (Lee et al., 2003, Sogame et al., 2003, Brodsky etal., 2000, Ollmann et al., 2000). Another way is to inhibit the activity of the JNK pathway; there are mutations that abolish JNK signalling at different levels (Xia and Karin, 2004). Also, the overexpression of puc, a negative regulator of the pathway results in effective suppression of JNK activity (Martín-Blanco etal., 1998).

\section{2) Preventing caspase activation}

The loss of $r p r$, hidand grimfunctions in embryos homozygous for the H99 deletion does not allow DIAP1 inactivation and effectively suppresses most apoptosis (White et al., 1994). The $\mathrm{H} 99$ deletion is embryonic lethal but clones of H99 imaginal cells proliferate normally. These cells show very low apoptotic levels after irradiation (our unpublished results). Even in heterozygous condition (H99/+) there is a substantial diminution of apoptosis (White et al., 1994). Another way to prevent caspase activation is to overexpress DIAP1 using the UAS-diap1 transgene; it blocks 
most of the apoptosis but not all (Ryoo et al., 2002). Finally, mutations or dominant negative forms of the initiator caspase Dronc, also prevent the activation of the effector caspase Drice (Mills et al., 2005).

\section{3) Preventing effector caspase function}

Mutations at the effector caspase Drice have been recently isolated (Kondo et al., 2006, Muro et al., 2006, Xu et al., 2006). However, the classical method to prevent effector caspase function is to use the baculovirus protein P35 (Hay et al., 1994). P35 blocks the function of Drice (without affecting Dronc), but allows its activation. A specific antibody recognises the processed form of Drice, even in the presence of the baculovirus protein. Apparently P35 binds to the Drice protein and impedes its protease activity (see Callus and Vaux, 2007).

\section{Developmental consequences of interfering with stress response apoptosis}

We have studied the consequences of interfering with the apoptotic response in flies subjected to irradiation (PérezGarijo et al., 2004, and unpublished results) and compared the effect of the interference at different stages of the apoptotic
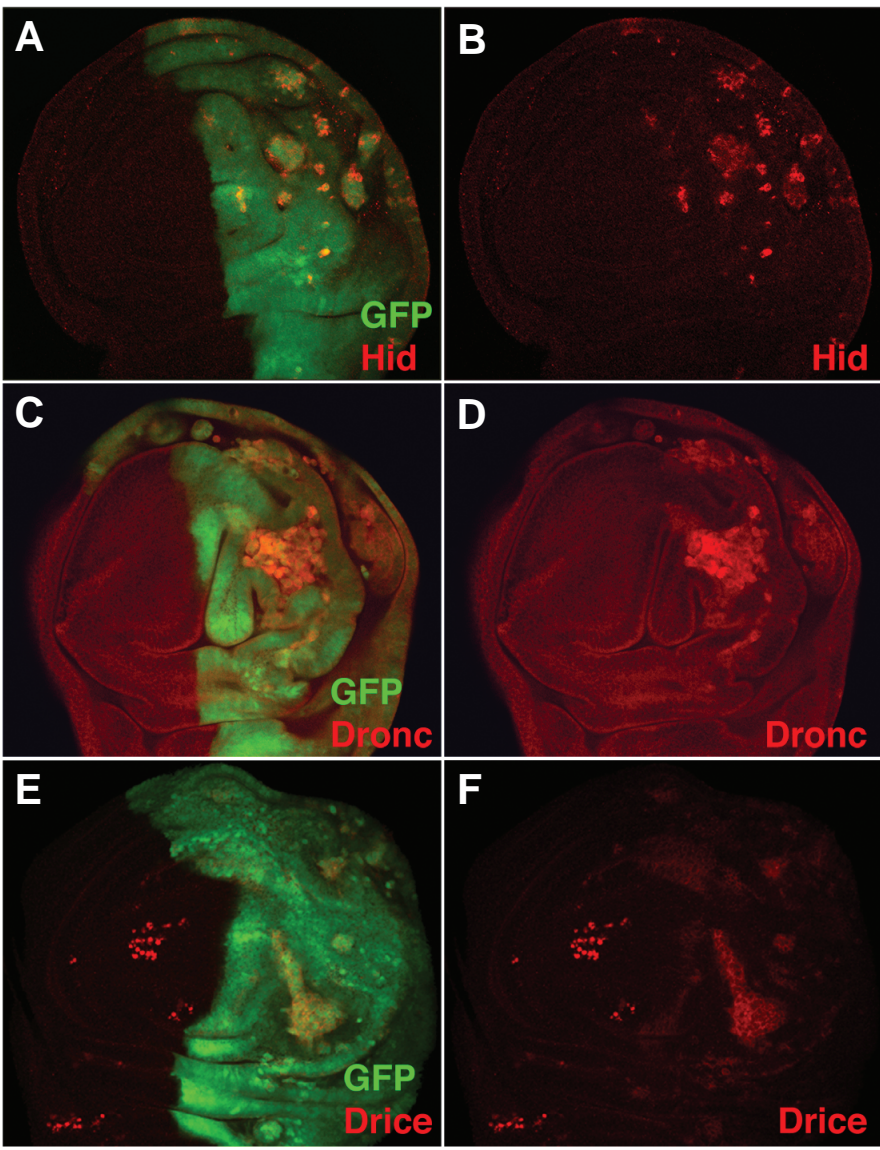

Fig. 3. Long term maintenance of the apoptotic program in undead cells. The wing discs shown are of genotype hh-Gal4>UAS-p35 UAS-GFP and were irradiated for apoptosis induction $96 \mathrm{~h}$ before fixation. The undead cells in the posterior compartment still show activity for hid $(\mathbf{A}, \mathbf{B})$, dronc, (C,D) and drice (E,F). program (Figs. 1,2).

The lack of activity of p53 either in p53 mutants or overexpressing the dominant negative form of the P53 protein causes a large diminution of the apoptotic response to X-rays: there is no activity of effector caspase as indicated by staining with a specific antibody (Fig. 2) or with the TUNEL method. Interestingly, this loss of apoptotic response does not appear to have an obvious effect on the development or morphology of the flies, although other possible effects on longevity or fertility have not been characterised. Similarly, the comparison of irradiated anterior and posterior compartments of hh-Gal4 >UAS-p53DN larvae in which apoptosis is suppressed in posterior but not in the anterior compartment does not reveal any significant difference. A similar result is found when caspases are not activated, as in the case of H99 homozygous cells or cells overexpressing DIAP1 (Fig. 2). The irradiation does not seem to produce any clear developmental aberration in these cells.

By contrast, interfering with the effector caspase Drice activity with P35 has major developmental consequences (Fig. 2 and Pérez-Garijo et al., 2004). In discs of genotype hh-Gal4>UASP35, Drice activity is inhibited in the posterior but not in the anterior compartment. This causes large overgrowths in the posterior compartment, which are associated with higher cell proliferation rate, as indicated by BrdU incorporation, and increased number of mitotic cells. A comparable result is obtained irradiating discs of genotype ap-Gal4>UAS-P35, but in this case the anomalies appear in the dorsal compartment. In the absence of irradiation, the presence of the heterologous P35 protein does not cause any significant alteration, except a shortening of vein 5 . It is worth to point out that similar aberrations appear when inducing apoptosis with heat shock (Pérez-Garijo et al., 2004) thus these effects are not a specific consequence of the X-ray induced apoptosis.

A striking feature of irradiated compartments containing P35 is the presence of groups of "undead cells", that is, the fraction of cells that as a consequence of the irradiation had initiated the apoptosis program but that are not allowed to die due to the blockage of the effector caspase. Although they are clearly abnormal in shape and size, undead cells in the wing disc differentiate wing structures (Pérez-Garijo et al., 2004, and unpublished results), indicating that they retain their original identity.

These cells possess virtually all the molecular markers of apoptosis, such low levels of Diap1 and high levels of Hid, Dronc or Drice proteins (Fig. 3). They behave as normal apoptotic cells and move towards the basal membrane of the epithelia. However, they show shape alterations that make them different from normal epithelial cells; they are rounded and larger (Fig. 4). The distribution of the different cytoskeleton protein in undead cells has not been studied. In discs irradiated at the first larval instar the undead cells still show the apoptotic markers at the end of the third instar, more than $96 \mathrm{hrs}$ after the end of the irradiation, indicating that the undead cell state has become permanent.

In addition to the apoptotic markers, many of these undead cells contain expression of the signalling genes decapentaplegic (dpp)and wingless (wg)(Fig. 4), known to be major patterning and growth organizers in the wing disc (reviewed in Tabata and Takei, 2004). This adventitious induction of $d p p$ and $w g$ has also been observed in other experiments (Huh et al., 2004, Ryoo et al., 2004 ) in which undead cells are produced by forcing expression 

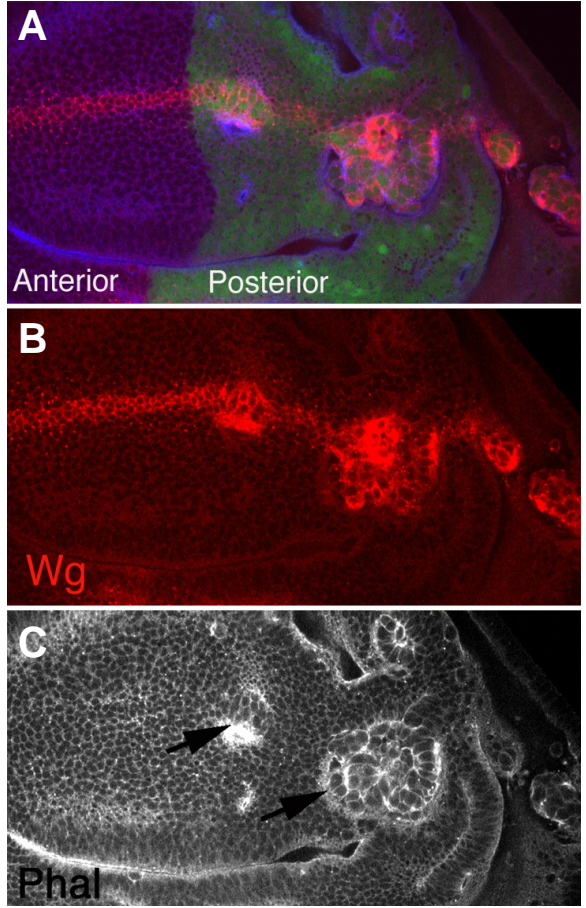

Fig. 4. Alterations of size and shape of undead cells. (A-C) Portion of the disc of genotype hh-Gal4UAS-p35 UAS-GFP stained for Wg (red) and phaloidin (A). Notice that the undead cells, which contain wg activity (B) are bigger than the surrounding cells and also have abnormal shape.

of the apoptotic genes rpror hidin cells that contain P35, thus it seems to be a general feature of undead cells.

The persistence of undead cells in irradiated $h h-G a / 4>U A S$ p35discs, coupled with their ectopic dpp and wgexpression, are most probably the causes of the abnormal growth of the P35containing compartments, although there is no direct proof of their involvement. However, the additional proliferation observed in compartments containing undead cells or in the vicinity of undead cells is non cell autonomous, pointing to the Dpp or Wg secreted signals as the responsible factors. There is also the possibility of other signals that may be activated in the undead cells.

Another interesting feature of undead cells is their ability to invade neighbour compartments. This is especially clear in $h$ hGal4>UAS-p35 irradiated discs; there are frequently finger-like extensions into the anterior compartments (Fig. 5), which are never observed in normal discs. This invasion does not appear to be a transgression of the A/P border similar to those reported for cells lacking engrailedactivity, for there is no mixing with anterior cells (reviewed in Irvine and Rauskolb, 2001). As shown in Fig. 5 the invading posterior cells still retain enfunction and do not gain ci activity; it seems that though these cells retain their original identity have nonetheless acquired a capacity to migrate.

Fig. 5. Migratory capacity of undead cells. The genotype of the discs is hh-Gal4>UAS-p35 UAS-GFP. Normally the antero-posterior compartment border in the wing disc is straight (see Fig. 2 C, F), but some of the undead cells in the posterior compartment acquire migratory properties and penetrate into the anterior compartment. Nevertheless the invading cells retain their original identity as indicated by the expression of engrailed (A,B) and by the lack of ci activity (C,D).
Undead cells can also be generated by over-expressing rpror hid or making diap 1\% clones and blocking cell death with p35 in posterior compartment (Huh et al., 2004, Ryoo et al., 2004). They exhibit the same set of properties (non autonomous induction of proliferation, $w g$ and $d p p$ activation) described for undead cells generated by irradiation. This clearly indicates that, independently of the type of stress event causing apoptosis, what is really important to generate undead cells is uncoupling apoptosis and cell death.

\section{Undead cells and compensatory proliferation}

The phenomenon of compensatory proliferation implies additional divisions of surviving cells after a stress event in order to restore the normal organ and body size. It would be expected then, that the stress event at the same time that eliminates a large number of cells, also generates a stimulus to proliferation.

The properties of undead cells may suggest a mechanism of compensatory proliferation based on their ability to induce cell proliferation in neighbour cells (Huh et al., 2004, Pérez-Garijo et al., 2004, Ryoo et al., 2004), possibly mediated by the secretion of the Dpp and Wg signals. It is known that both Dpp and Wg can function as mitogens in the wing disc (Martín-Castellanos and Edgar, 2002, Neumann and Cohen, 1996; Martin et al., 2004). This model implies that normal apoptotic cells also emit the Dpp and $\mathrm{Wg}$ signals thus providing an additional proliferation stimulus to the cells that survive the treatment. This would result in the necessary extra growth to restore the normal cell population. Although the synthesis of the Dpp and Wg proteins is not easy to observe in normal short-lived apoptotic cells, in certain conditions these products have been visualised (Ryoo et al., 2004; Peréz Garijo et al., 2004). Thus the acquisition of $d p p$ and wgactivity is not only a feature of undead cells but also occurs in genuine apoptotic cells.

In any case, the implication of Dpp and $\mathrm{Wg}$ in compensatory
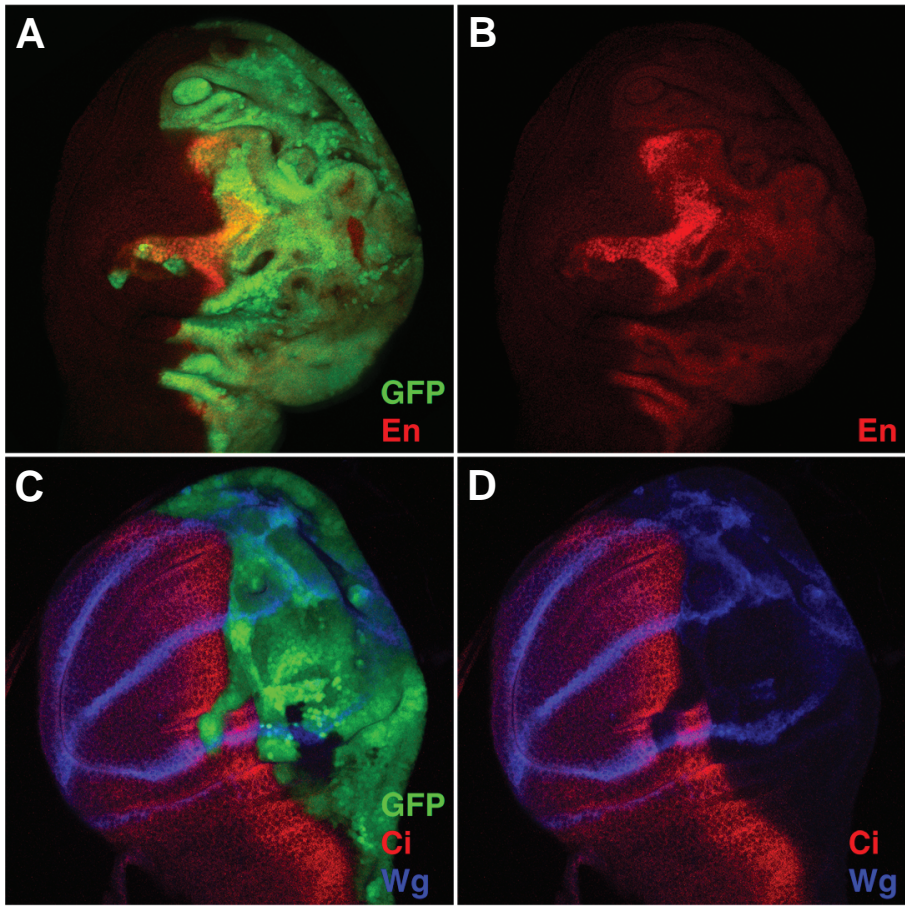
proliferation is an open question. Ryoo and colleagues abrogated the extra-growth caused by undead cells blocking the response to $\mathrm{Wg}$ signalling. They also showed that the activation of $\mathrm{Wg}$ pathway can induce cell proliferation, suggesting a role for $\mathrm{Wg}$. However, while suggestive, these experiments do not address directly the role of $w g$ and dppin compensatory proliferation. The response to irradiation of discs or compartments deficient in either $d p p, w g$ or both may provide an answer to this question.

\section{Concluding remarks}

One of the main features of undead cells is that they express dppand $w g$ (and perhaps other signalling genes) ectopically. This phenomenon raises a few problems. An obvious one is how their expression is induced. In particular, the activation of $d p p$ poses the question of how a posterior cell can activate $d p p$ in the presence of the Engrailed product, which inhibits the Hh pathway necessary to induce $d p p$ activity (reviewed in Lawrence and Struhl, 1996). This suggests that $d p p$ may be activated by a mechanism not dependant on $\mathrm{Hh}$. The observation that in absence of JNK activity there is no $w g$ and $d p p$ activation may suggest that JNK signalling is involved.

Another peculiarity is that although $\mathrm{Wg}$ and Dpp expression are mutually exclusive in almost every Drosophila tissue (reviewed in Tabata, 2001), they are often co-expressed in undead cells, suggesting that the functional properties of these two pathways are not the same as in normal cells.

One interesting feature of undead cells is that they retain their apoptotic nature indefinitely, in some cases for the entire larval period. How they keep expression of hid, dronc, drice, wgand dpp is not well known. Recent work (McEwen and Peifer, 2005) has shown that both $p 53$ and the JNK pathway function upstream caspase activation: both $p 53$ and JNK are able to activate rpr. In the case of p53, Wells and colleagues (2006) have shown that it also functions downstream dronc. This suggests that $p 53$ is part of a feedback loop to sustain the activity of the apoptotic machinery in undead cells

Finally, the discovery of the signalling properties of apoptotic cells as revealed by the undead cells may have some implications in human disease. Apoptosis inhibition is frequently associated with tumour formation and the undead cells represent a class of cells immune to apoptosis. Moreover, they remain indefinitely alive within the tissue and persistently produce mitogenic signals such as Dpp and $\mathrm{Wg}$. These signals may stimulate proliferation of neighbour cells and therefore contribute to the formation of a tumour. Furthermore, another feature of undead cells, their ability to migrate, may also be an important contributing factor.

There is no evidence that undead cells are formed in mammalian tissues, but the mechanism of caspase activation, the upstream effectors ( $p 53, \mathrm{JNK}$ ) and the signals involved (Dpp, Wg) are conserved in insects and vertebrates. Thus it is possible to imagine a parallel situation in mammalian cells. Mammalian cells often enter apoptosis after a viral infection (Thomson, 2001) to prevent the proliferation of the virus in the tissue, but animal viruses frequently encode caspase inhibitors to prevent death of host cells (see Callus and Vaux, 2007), the P35 protein of baculovirus origin is just one example. Thus a virus infection may generate in mammalian tissues a class of undead cells, which stimulate the growth of the infected tissue.
The lack or diminution of caspase activity due to mutation may also be a tumorigenic factor, as it would prevent the elimination of apoptotic cells that appear after stress, e.g. heat shock, drug exposition, viral infection, etc. In fact the levels of caspase activity are a diagnostic feature in cancer patients (Fennell, 2005)

\section{References}

MADA, T., FUJIMURA-KAMADA, K., NISHIDA, Y. and MATSUMOTO, K. (1999). Distorsion of proximodistal information causes JNK-dependent apoptosis in Drosophila wing. Nature 400: 166-169.

BAEHRECKE, E.H. (2002). How death shapes life during development. Nat Rev Mol Cell Biol3: 779-87.

BRODSKY, M.H., NORDSTROM, W., TSANG, G., KWAN, E., RUBIN, G.M. and ABRAMS, J.M. (2000). Drosophila p53 binds a damage response element at the reaper locus. Cel/101: 103-13.

BRODSKY, M.H., WEINERT, B.T., TSANG, G., RONG, Y.S., MCGINNIS, N.M., GOLIC, K.G., RIO, D.C. and RUBIN, G.M. (2004). Drosophila melanogaster MNK/Chk2 and p53 regulate multiple DNA repair and apoptotic pathways following DNA damage. Mol Cell Bio/24: 1219-31.

CALLUS, B.A. and VAUX, D.L. (2007). Caspase inhibitors: viral, cellular and chemical. Cell Death Differ 14: 73-8.

CASHIO, P., LEE, T.V. and BERGMANN, A. (2005). Genetic control of programmed cell death in Drosophila melanogaster. Semin Cell Dev Biol16: 225-35.

COLOMBANI, J., POLESELLO, C., JOSUE, F. and TAPON, N. (2006). Dmp53 activates the Hippo pathway to promote cell death in response to DNA damage. Curr Biol16: 1453-8.

CHEN, P., NORDSTROM, W., GISH, B. and ABRAMS, J.M. (1996). grim, a novel cell death gene in Drosophila. Genes Dev10: 1773-82.

DANIAL, N.N. and KORSMEYER, S.J. (2004). Cell death: critical control points. Cel/ 116: 205-19.

DOMINGOS, P.M. and STELLER, H. (2007). Pathways regulating apoptosis during patterning and development. Curr Opin Genet Dev 17: 294-9.

FENNELL, D.A, (2005). Caspase regulation in non-small cell lung cancer and its potential for therapeutic exploitation. Clinical Cancer Research 11 2097-2105

FINK, S.L. and COOKSON, B.T. (2005). Apoptosis, pyroptosis, and necrosis: mechanistic description of dead and dying eukaryotic cells. Infect Immun 73: 1907-16.

GRAVES, B.J. and SCHUBIGER, G. (1982). Cell cycle changes during growth and differentiation of imaginal leg discs in Drosophila melanogaster. Dev Bio/93: 104-10.

GREENWOOD, J. and GAUTIER, J. (2005). From oogenesis through gastrulation: developmental regulation of apoptosis. Semin Cell Dev Bio/16: 215-24.

HAY, B.A. and GUO, M. (2006). Caspase-dependent cell death in Drosophila. Annu Rev Cell Dev Bio/22: 623-50.

HAY, B.A., HUH, J.R. and GUO, M. (2004). The genetics of cell death: approaches, insights and opportunities in Drosophila. Nat Rev Genet 5: 911-22.

HAY, B.A., WOLFF, T. and RUBIN, G.M. (1994). Expression of baculovirus P35 prevents cell death in Drosophila. Development 120: 2121-9.

HAYNIE, J.L. and BRYANT, P.J. (1977). The effects of X-rays on the proliferation dynamics of Cells in the imagina wing disc of Drosophila melanogaster. Wilhelm Roux's Archives 183: 85-100.

HUH, J.R., GUO, M. and HAY, B.A. (2004). Compensatory proliferation induced by cell death in the Drosophila wing disc requires activity of the apical cell death caspase Dronc in a nonapoptotic role. Curr Bio/14: 1262-6.

IRVINE, K.D. and RAUSKOLB, C. (2001). Boundaries in development: formation and function. Annu Rev Cell Dev Bio/17: 189-214.

JAKLEVIC, B.R. and SU, T.T. (2004). Relative contribution of DNA repair, cell cycle checkpoints, and cell death to survival after DNA damage in Drosophila larvae. Curr Bio/14: 23-32.

KONDO, S., SENOO-MATSUDA, N., HIROMI, Y. and MIURA, M. (2006). DRONC coordinates cell death and compensatory proliferation. Mol Cel/ Bio/26: 725868. 
LAWRENCE, P.A. and STRUHL, G. (1996). Morphogens, compartments, and pattern: lessons from drosophila? Cel/85: 951-61.

LEE, J.H., LEE, E., PARK, J., KIM, E., KIM, J. and CHUNG, J. (2003). In vivo p53 function is indispensable for DNA damage-induced apoptotic signaling in Drosophila. FEBS Lett550: 5-10.

LOHMANN, I., MCGINNIS, N., BODMER, M. and MCGINNIS, W. (2002). The Drosophila Hox gene deformed sculpts head morphology via direct regulation of the apoptosis activator reaper. Ce//110: 457-66.

LU, W.J. and ABRAMS, J.M. (2006). Lessons from p53 in non-mammalian models. Cell Death Differ 13: 909-12.

MANJON, C., SANCHEZ-HERRERO, E. and SUZANNE, M. (2007). Sharp boundaries of Dpp signalling trigger local cell death required for Drosophila leg morphogenesis. Nat Cel/ Bio/9: 57-63.

MARTíN, F.A., PÉREZ-GARIJO, A., MORENO, E. and MORATA, G. (2004). The Brinker Gradient Controls Wing Growth in Drosophila. Development131 49214930

MARTÍN-BLANCO, E., GAMPEL, A., RING, J., VIRDEE, K., KIROV, N., TOLKOVSKY, A.M. and MARTINEZ, A.A. (1998). puckered encodes a phosphatase that mediates a feedback loop regulating JNK activity during dorsal closure in Drosophila. Genes Dev12: 557-70.

MARTÍN-CASTELLANOS, C. and EDGAR, B.A. (2002). A characterization of the effects of Dpp signaling on cell growth and proliferation in the Drosophila wing. Development 129: 1003-13.

MCEWEN, D.G. and PEIFER, M. (2005). Puckered, a Drosophila MAPK phosphatase, ensures cell viability by antagonizing JNK-induced apoptosis. Deve/opment 132: 3935-46.

MILÁN, M., CAMPUZANO, S. and GARCÍA-BELLIDO, A. (1997). Developmental parameters of cell death in the wing disc of Drosophila. Proc Nat/Acad SciUSA 94: 5691-6.

MILLS, K., DAISH, T. and KUMAR, S. (2005). The function of the Drosophila caspase DRONC in cell death and development. Cell Cycle 4: 744-6.

MORENO, E., BASLER, K. and MORATA, G. (2002). Cells compete for decapentaplegic survival factor to prevent apoptosis in Drosophila wing development. Nature 416: 755-9.

MURO, I., BERRY, D.L., HUH, J.R., CHEN, C.H., HUANG, H., YOO, S.J., GUO, M., BAEHRECKE, E.H. and HAY, B.A. (2006). The Drosophila caspase Ice is important for many apoptotic cell deaths and for spermatid individualization, a nonapoptotic process. Development 133: 3305-15.

NEUMANN, C.J. and COHEN, S.M. (1996). Distinct mitogenic and cell fate specification functions of wingless in different regions of the wing. Development 122: $1781-9$.

OLLMANN, M., YOUNG, L.M., DI COMO, C.J., KARIM, F., BELVIN, M., ROBERTSON, S., WHITTAKER, K., DEMSKY, M., FISHER, W.W., BUCHMAN, A. et al. (2000). Drosophila p53 is a structural and functional homolog of the tumor suppressor p53. Cel/101: 91-101.
PÉREZ-GARIJO, A., MARTíN, F.A. and MORATA, G. (2004). Caspase inhibition during apoptosis causes abnormal signalling and developmental aberrations in Drosophila. Development 131: 5591-8.

RIEDL, S.J. and SHI, Y. (2004). Molecular mechanisms of caspase regulation during apoptosis. Nat Rev Mol Cell Bio/5: 897-907.

RYOO, H.D., BERGMANN, A., GONEN, H., CIECHANOVER, A. and STELLER, H. (2002). Regulation of Drosophila IAP1 degradation and apoptosis by reaper and ubcD1. Nat Cel/ Bio/4: 432-8.

RYOO, H.D., GORENC, T. and STELLER, H. (2004). Apoptotic cells can induce compensatory cell proliferation through the JNK and the Wingless signaling pathways. Dev Cel/7: 491-501.

SAUCEDO, L.J. and EDGAR, B.A. (2007). Filling out the Hippo pathway. Nat Rev Mol Cell Bio/8: 613-621.

SOGAME, N., KIM, M. and ABRAMS, J.M. (2003). Drosophila p53 preserves genomic stability by regulating cell death. Proc Nat/ Acad Sci USA 100: 4696701.

SONG, Y.H. (2005). Drosophila melanogaster: a model for the study of DNA damage checkpoint response. Mol Cells 19: 167-79.

TABATA, T. (2001). Genetics of morphogen gradients. Nat Rev Genet2: 620-30.

TABATA, T. and TAKEI, Y. (2004). Morphogens, their identification and regulation. Development 131: 703-12.

THOMSON, B.J. (2001). Viruses and apoptosis. Int J Exp Patho/82: 65-76.

WELLS, B.S., YOSHIDA, E. and JOHNSTON, L.A. (2006). Compensatory proliferation in Drosophila imaginal discs requires Dronc-dependent p53 activity. Curr Biol16: 1606-15.

WHITE, K., GRETHER, M.E., ABRAMS, J.M., YOUNG, L., FARRELL, K. and STELLER, H. (1994). Genetic control of programmed cell death in Drosophila. Science 264: 677-83.

WICHMANN, A., JAKLEVIC, B. and SU, T.T. (2006). lonizing radiation induces caspase-dependent but Chk2- and p53-independent cell death in Drosophila melanogaster. Proc Natl Acad Sci USA 103: 9952-7.

WING, J.P., SCHREADER, B.A., YOKOKURA, T., WANG, Y., ANDREWS, P.S. HUSEINOVIC, N., DONG, C.K., OGDAHL, J.L., SCHWARTZ, L.M., WHITE, K. et al. (2002). Drosophila Morgue is an $\mathrm{F}$ box/ubiquitin conjugase domain protein important for grim-reaper mediated apoptosis. Nat Cell Bio/4: 451-6.

WOLFF, T. and READY, D.F. (1991). Cell death in normal and rough eye mutants of Drosophila. Development 113: 825-39.

XIA, Y. and KARIN, M. (2004). The control of cell motility and epithelial morphogenesis by Jun kinases. Trends Cel/ Bio/14: 94-101.

XU, D., WANG, Y., WILLECKE, R., CHEN, Z., DING, T. and BERGMANN, A (2006). The effector caspases drICE and dcp-1 have partially overlapping functions in the apoptotic pathway in Drosophila. Cell Death Differ 13: 1697706 . 


\section{Related, previously published Int. J. Dev. Biol. articles}

See our recent Special Issue Ear Development edited by Fernando Giraldez and Bernd Fritzsch at: http://www.ijdb.ehu.es/web/contents.php?vol=51\&issue=6-7

Molecular Drosophila retinal pigment cell death is regulated in a position-dependent manner by a cell memory gene Nicolas Dos-Santos, Thomas Rubin, Fabienne Chalvet, Pierre Gandille, Frederic Cremazy, Jacqueline Leroy, E. Boissonneau and Laurent Théodore

Int. J. Dev. Biol. (2008) 52: 21-31

Drosophila Mrityu encodes a BTB/POZ domain-containing protein and is expressed dynamically during development Jamie C. Rusconi and Uma Challa Int. J. Dev. Biol. (2007) 51: 259-263

PVF1/PVR signaling and apoptosis promotes the rotation and dorsal closure of the Drosophila male terminalia

Ana Macías, Nuria M. Romero, Francisco Martín, Leonardo Suárez, Alberto L. Rosa and Ginés Morata

Int. J. Dev. Biol. (2004) 48: 1087-1094

Dynamics of decapentaplegic expression during regeneration of the Drosophila melanogaster wing imaginal disc Jaakko Mattila, Leonid Omel Yanchuk and Seppo Nokkala Int. J. Dev. Biol. (2004) 48: 343-347

The origins of axial patterning in the metazoa: how old is bilateral symmetry?

John R Finnerty

Int. J. Dev. Biol. (2003) 47: 523-529

Expression of the fibroblast activation protein during mouse embryo development.

J Niedermeyer, P Garin-Chesa, M Kriz, F Hilberg, E Mueller, U Bamberger, W J Rettig and A Schnapp

Int. J. Dev. Biol. (2001) 45: 445-447

Requirement of Drosophila I(2)gl function for survival of the germline cells and organization of the follicle cells in a columnar epithelium during oogenesis.

C De Lorenzo, D Strand and B M Mechler

Int. J. Dev. Biol. (1999) 43: 207-217

The expression of MDP-1, a component of Drosophila embryonic basement membranes, is modulated by apoptotic cell death.

M Hortsch, A Olson, S Fishman, S N Soneral, Y Marikar, R Dong and J R Jacobs

Int. J. Dev. Biol. (1998) 42: 33-42

Crescent, a novel chick gene encoding a Frizzled-like cysteine-rich domain, is expressed in anterior regions during early embryogenesis. P L Pfeffer, E M De Robertis and J C Izpisua-Belmonte Int. J. Dev. Biol. (1997) 41: 449-458

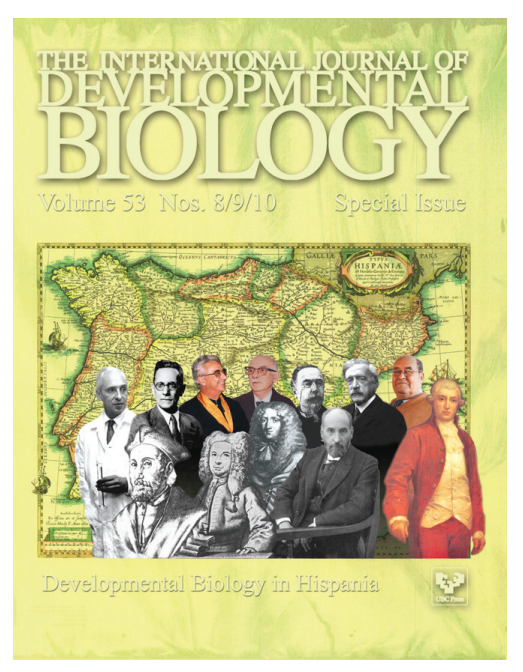

5 yr ISI Impact Factor $(2008)=3.271$

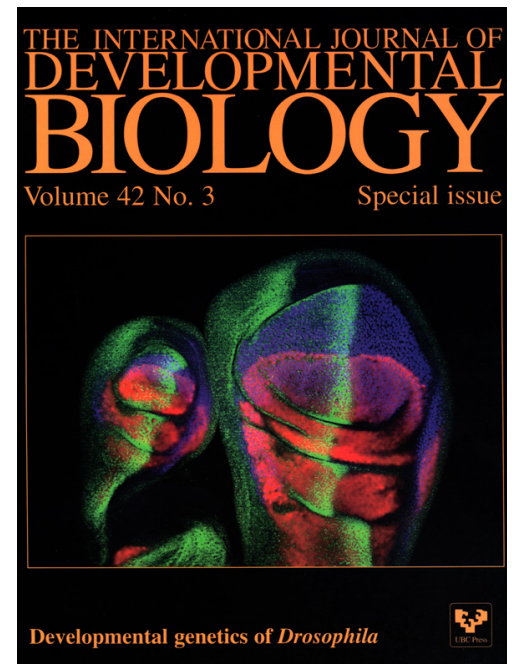

